\title{
The Informational Professional and His Six Senses
}

\author{
Akanbiemu Adetola Adebisi \\ Learning Resources Centre/Library \\ National Open University Of Nigeria, Abuja, Nigeria \\ Otuza Chima Evans, PhD \\ Department Of Information Resources Management \\ Babcock University, Ogun, Nigeria
}

\begin{abstract}
This paper discuses a mental perception depicting competencies of information professional. In being a relevant and effective information professional, just like a human being is endowed with senses of touch, taste, hearing, seeing so must information professionals have a sense of collaboration, creative and critical thinking, communication, culture and credibility. Information professionals need to create a positive image by building mental competencies; these competencies are what we refer to as his six senses. Information professionals are charged with the responsibility of creating, storing, organising and disseminating information. Every information professional needs information to plan, control and make decisions but having information to perform these tasks are not enough but having the sense of collaboration, to make work quicker and easier, being creative to be innovative, critical in his thinking to indicate errors and create solutions. He should also be able to communicate effectively, embrace culture and have credibility as his six senses.
\end{abstract}

Keywords: information professional, collaboration, creative thinking, critical thinking, communication, culture, credibility

\section{INTRODUCTION}

Sense is an ability to understand, recognize, value, or react to something, especially any of the five physical abilities to see, hear, smell, taste, and feel (Cambridge Advanced Learners Dictionary, 2016) . Sense is likened to depict competencies that an information professional should have ability to understand, recognize, value and most importantly have. Information profession is a service profession and makes use of information as a resource such to perform and deliver his services effectively. Information professional are professionals tasked with duties of collecting, recording, organizing, storing, preserving, retrieving, and disseminating printed or digital information resources. What information professionals have in common is the ability to provide timely, accurate, and actionable information to their clients (Association of Independent Information professional, 2016). An information professional usually has a number of different specializations and definitely different training, education and skills. The following are kinds of Information disciplines ; library science, information science, records management, museum studies, document and genre studies, knowledge management, informatics, information systems (Bates \& Maack, 2010; Bates, 2007).

The objective of this paper is to look at the competencies depicting the six senses an information professional should have. For this reason, this paper will explain the different senses and why it's essential as a sense. Conclusion and recommendation will be made. 


\section{FIRST SENSE - SENSE OF COLLABORATION}

Lai (2011) defined Collaboration as the "mutual engagement of participants in a coordinated effort to solve a problem together" (p. 3). Collaboration thereby involves individuals working together to achieve a defined and common purpose. This implies that in working together, ideas and skills are shared. One of the biggest contributors of success in any organisation is whether or not its employees perform together as a team. With increasing competitions in Information centres, it has become extremely important to encourage collaboration in the work place, in order to improve productivity and promote healthy employee relationship. As compared to individuals who work on their own, working in teams enables employees to be faster and quicker in their work. Collaborating also makes employees more responsible, which also increases their motivation levels, especially when teams work virtually (Boyer, 2016).

For an information professional, there are a lot of benefits in having a sense of collaboration: benefits for himself and benefits for the organisation. It promotes self-analysis by challenging employees to think about their competencies thereby serving as a mirror that gives them a glimpse of their strength and weaknesses. It results in problem solving; it makes you look at the bigger picture, definitely because no two people are the same thereby identifying how they can complement one another. Collaboration also teaches because employees are indirectly learning new things from one another (Boyer, 2016). Callahan, Schenk and White (2012) also added that collaboration generates new ideas and new solutions that emerge from the interplay of these perspectives, he further stated three types of collaboration: team collaboration, collaboration and network collaboration.

\section{Team Collaboration}

In team collaboration, the focus of this group is task interdependencies, expected reciprocity, and explicit time-lines and goals. To achieve the goal, members must fulfil their interdependent tasks within the stated time. The participants are to cooperate equally and will receive equal recognition. Team collaborations can also occur with information professionals that work with external bodies, but there is always a clear mandate and defined roles. It could also be called creative collaboration in that it's intended to create something. It is goal-oriented, and has a defined team .The objective for this type of collaboration is to be able to achieve what seems too much for a single individual either because it is too much work or it requires a variety of skills or perspective to achieve. Examples of information professionals that team collaborate involve research and development within and out of their information centre in a bid to solving a problem. (Callahan et al.2012)

\section{Community Collaboration}

In community collaboration or connective, the focus is more on learning rather than on task. Knowledge sharing is more important than building projects. Members may go to their communities to help solve their problems by asking questions and getting advice, then taking that advice back home to implement in their teams. Community collaborations may also give rise to more formalised team collaborations. As people get to know each other, they can identify good fits for team members and draw new talent into their teams. (Callahan, et al., 2012)

\section{Network Collaboration}

In Network collaboration or compounding collaboration, collaboration that starts with individual action and self-interest, which then accrues to the network as individuals contribute or seek something from the network. This form of collaboration is driven by the advent of social media (tools that help us connect and interact online), ubiquitous internet connectivity and the ability to connect with diverse individuals across distance and time. It is a response to 
the overwhelming volume of information we are creating. It's impossible for an individual to cope on their own. So network collaboration become mechanisms for knowledge and information capture filtering and creation. The reason why it's called compounding collaboration is to ensure that whatever our efforts are, they are being leveraged to the greatest extent (Callahan et al., 2012) .To achieve this, we need to be able to capture ideas and information. The field of Knowledge Management supports this type of collaboration (Dalkir, 2005), its implications are that only the most formal, documented and recognized knowledge is captured. Examples are social book marking.

Information professionals should have a sense of all types of collaboration listed above in being relevant and being 21st century information professional. This will lead to them being beneficial to their information centres; it will increase knowledge sharing, innovative thinking as a result of problem solving, employee retention and job satisfaction. There are a range of digital collaboration tools an information professional can and should utilize: Online team workspaces, Company wiki, Forums, Blogging, Instant messaging, Facebook-like profile pages. Despite the numerous advantages and benefits of collaboration, there are still some reasons why information professionals are not collaborative. They include unhealthy competition amongst employees, Lack of organisational culture that encourages collaboration, having too many people involved. Missing link in communication and having negative mind-sets (Hansen, 2016)

\section{SECOND SENSE - SENSE OF CREATIVE THINKING}

Sharma (2016) defines creative thinking "as a controlled thinking in which the creative thinker whether artist, writer or a scientist is trying to create something new. It involves characteristics of both reasoning and imagination. Creative thinking is a process in which the individual generates an original, unusual and productive solution to a problem" (para. 1). He further defined it as "personal, imaginative thinking which produces a new, novel and useful solution" (para. 2). From the above definition creative thinking could be said to new on the effect that no one has thought of it before. The emphasis from the definition is the word new. So if it's new, it's creative thinking. This brings us to another word whose definition emphasised on the same word new: innovation. Luecke and Katz (2003) defined innovation as the introduction of a new thing or method. The basis for innovation is creativity and originality and for innovation to occur, creative ideas and the ability to convert such ideas into action and make a change must be available. The result of this is usually a peculiar and precise change in either, products, services or methods provided in the organization.

For an information professional to be creative in his thinking, he has to be either a convergent or divergent thinker (Wilson, 2016). Divergent thinkers usually have the ability to elaborate, and think of diverse and original ideas with fluency and speed. The brainstorm a lot of the time .divergent thought patterns asks question like this: What if . . ? How about . . ? Could we try this or that idea ...? Their main aim while thinking is to find solutions, to generate new and different ideas. Convergent thinkers usually have ability to use logical and evaluative thinking to critique and narrow ideas to ones best suited for given situations, or set criteria This type of thinkers are best needed when crucial and well-formed decisions are to be made after appraising an array of ideas, information, or alternatives.

Having a sense of critical thinking is a skill that is needed across all disciplines and it will always be in demand. However, as an information professional, he should develop his creative thinking sense so he can enjoy the numerous benefits attached to being a creative thinker. Being a creative thinker is one of the most important marketable skills, it can open doors to opportunity, a whole new realm of opportunity and it promotes initiatives and optimism (Kim, 
2014). It is also important because it helps them to be innovative by creating new ideas and methods. To be creative in his thinking, He must also have the following characteristics: curious, seeks problems, enjoys challenge, optimistic, able to suspend judgment, comfortable with imagination, sees problems as opportunities, sees problems as interesting, problems are emotionally acceptable, challenges assumptions „doesn't give up easily: perseveres, works hard.(Harris, 2012).

Olson (1999) agreed also that as information professionals who would be critical thinkers should, as well have attributes associated with creative problem solving abilities. They are:

- Fluency - The ability to generate a number of ideas so that there is an increase of possible solutions or related products.

- Flexibility - The ability to produce different categories or perceptions whereby there are a variety of different ideas about the same problem or thing.

- Elaboration - The ability to add to, embellish, or build on an idea or product.

- Originality - The ability to create fresh, unique, unusual, totally new, or extremely different ideas, products or services.

- Complexity - The ability to conceptualize difficult, intricate, many layered or multifaceted ideas or products.

- Risk-taking - The willingness to be courageous, adventuresome, daring - trying new things or taking risks in order to stand apart.

- Imagination - The ability to dream up, invent, or to see, to think, to conceptualize new ideas or products - to be ingenious.

- Curiosity - The trait of exhibiting probing behaviours, asking and posing questions, searching, being able to look deeper into ideas, and the wanting to know more about something.

It could also be said that an information professional with high creative thinking skill is one having his intellect invested and busy, such a professional is a major asset to whichever organization he belongs. He is not only a creative thinker but an inventor and a discoverer.

\section{THIRD SENSE - SENSE OF CRITICAL THINKING}

Naturally, everyone thinks. . It is our nature to do so. Fundamentally, all thinking does not have the same quality. But much of our thinking, left to itself, is biased, distorted, partial, uninformed or down-right prejudiced. Yet the quality of our life and profession and that of what we produce, make, or build depends precisely on the quality of our thought. (Foundations of Critical Thinking, 2015). Excellence in thought, however, must be systematically cultivated. According to American Philosophical Association Delphi Report, (1990) critical thinking has been defined as, "The process of purposeful, self-regulatory judgment. The Process gives reasoned consideration to evidence, contexts, conceptualizations, methods and criteria." Paul \& Elder (2008) summarised the essence of critical thinking as follows: "the art of thinking in such a way as to: Identify its strengths and weaknesses, and recast it in improved form where necessary" (p. 20). This then implies that an information professional must be skilled in analytic, evaluative and creative thinking.

\section{The Essential Dimensions of Critical Thinking}

Elder, Paul and Cosgrove (2007) developed five dimensions of critical thinking as the analysis of thought, the assessment of thought, the dispositions of thought, the skills and abilities of thought and the obstacles or barriers to critical thought. Though we separate these functions for purposes of theoretical clarity, we nevertheless argue that each must be involved if the other two are to be effective.As other professions like business executives, engineers, analysts would critically think so would an information professional should critically think. 


\section{Main Standards of Critical Thinking for Information Professional}

Critical thinking includes a complex combination of skills. According to Paul and Elder (2006), the standards are: accuracy, precision, relevance, depth, breadth, logic, significance and fairness. Facione (1998) in American Psychological Association Delphi Report displays the following characteristics of critical thinkers as follows:

- inquisitiveness with regard to a wide range of issues

- concern to become and remain well-informed

- alertness to opportunities to use critical thinking

- self-confidence in one's own abilities to reason

- open-mindedness regarding divergent world views

- flexibility in considering alternatives and opinions

- understanding of the opinions of other people

- fair-mindedness in appraising reasoning

- honesty in facing one's own biases, prejudices, stereotypes, or egocentric tendencies

- prudence in suspending, making or altering judgments

- willingness to reconsider and revise views where honest reflection suggests that

A well trained information professional with the sense of critical thinking:

- raises vital questions and problems, formulating them clearly and precisely;

- gathers and assesses relevant information, using abstract ideas to interpret it effectively;

- comes to well-reasoned conclusions and solutions, testing them against relevant criteria and standards;

- thinks open minded within alternative systems of thought, recognizing and assessing, as need be, their assumptions, implications, and practical consequences; and

- communicates effectively with others in figuring out solutions to complex problems.(Foundations of Critical Thinking, 2015)

An information professional with Critical thinking is, summarised to be a self-monitored, selfdisciplined and self-corrective in thinking because it requires the use of requires rigorous standards of excellence and mindful command of their use. It entails effective communication and problem solving abilities and a commitment to delivering his duties.

\section{FOURTH SENSE - SENSE OF COMMUNICATION}

Communication is simply the act of transferring information from one place to another. Although this is a simple definition, when we think about how we may communicate the subject becomes a lot more complex. There are various categories of communication and more than one may occur at any time. The different categories of communication include:

- Spoken or Verbal Communication: face-to-face, telephone, radio or television and other media.

- Non-Verbal Communication: body language, gestures, how we dress or act - even our scent.

- Written Communication: letters, e-mails, books, magazines, the Internet or via other media.

- Visualizations: graphs and charts, maps, logos and other visualizations can communicate messages (Robin \& Timothy, 2013). 


\section{The Communication Process}

A message or communication is sent by the sender through a communication channel to a receiver, or to multiple receivers. The sender must encode the message (the information being conveyed) into a form that is appropriate to the communication channel, and the receiver(s) then decodes the message to understand its meaning and significance. Misunderstanding can occur at any stage of the communication process. Effective communication involves minimizing potential misunderstanding and overcoming any barriers to communication at each stage in the communication process. An effective communicator understands their audience, chooses an appropriate communication channel, hones their message to this channel and encodes the message to reduce misunderstanding by the receiver(s). They will also seek out feedback from the receiver(s) as to how the message is understood and attempt to correct any misunderstanding or confusion as soon as possible. Receivers can use techniques such as Clarification and Reflection as effective ways to ensure that the message sent has been understood correctly (Skillsyouneed.com, 2016).

Communication has a fundamental role to play in information profession. It is therefore very important that communication skills among colleagues are effective. Australian Institute of Business (2014) stated some reasons why information professionals need effective communication skills:

\section{Builds and maintains relationships}

Relationships should be built and maintained by positive encounters with others in the profession. Effective communication skills will help to achieve this without effective communication skills, it will be difficult to properly construct and foster productive relationships.

\section{Facilitates innovation}

Effective communication makes employees feel comfortable in openly communicating new ideas, by so doing, cooperation and innovation will be at an all-time high. In addition, if professionals are unable to pass their ideas across due to ineffective communication skills, it's likely that the idea will not be implemented to its full potential and the organisation might also lack innovative ideas.

\section{Builds an effective team}

A more cohesive and effective team will emerge. If open communication within a workplace is encouraged, Good communication within a team also tends to boost employee morale. When employees feel that they are well informed of the company's direction and vision, they will feel more secure within their role. Regular internal communication can also lead to an improved work ethic if professionals are reminded of achievements and feel that they are working towards a common goal.

\section{Contributes to growth of the company}

The easiest way for the collapse of any organisation is when there is a lack of communication. Whilst that is a bold statement - without proper communication internally and externally, most organisations will struggle to survive. Effective Communication can also lead to productivity, commitment and helps to avoid unnecessary delays in the implementation of policies. 


\section{Ensures transparency}

When regularly communicating both internally and externally, organisations remain more transparent. This is important in building trust among professionals, services and also internally when it comes to the trust that employees have in higher management.

It should be noted that effective workplace communication is important in information centres with workplace diversity. Good communication skills help to reduce the barriers of language and cultural differences. Information centres that provide communication training to domestic and international employees reap the benefits of effective workplace communication. Companies can avoid cultural confusion and miscommunication by training international employers early in their careers or on recruitment and on a regular basis. Effective communication causes productivity to increase, errors to decrease and operations to run smoother.

Information professional should improve and build their sense of communication; this can increase their morale, and produce a good healthy environment. When information professional are satisfied with their jobs, they are able to efficiently perform their duties with a positive attitude. Lack of good communication can lead to frustration and confusion which can bed unhealthy relationships among employee and affect the services that will be delivered users/clients.

\section{FIFTH SENSE - SENSE OF CULTURE}

Having a sense of Culture is like having a personality. In a person, the personality is made up of the values, beliefs, underlying assumptions, interests, experiences, upbringing, and habits that create a person's behaviour. Having said that, Heathfield (2016) defined culture as being made up of the values, beliefs, underlying assumptions, attitudes, and behaviours shared by a group of people. It could be said that culture is a behaviour that occurs when a set of generally unspoken and written rues are set for working together. The culture of a workplace is them made up of all the real life experiences that each professional brigs the workplace. Culture is particularly influenced by the organization's founder, executives, and other managerial staff because of their role in decision making and strategic direction. Chatman and Kehn, (1994) listed seven primary characteristics that seem to capture the essence of any organization's culture:

1. Innovation and risk taking. The degree to which employees are encouraged to be innovative and take risks.

2. Attention to detail. The degree to which employees are expected to exhibit precision, analysis, and attention to detail.

3. Outcome orientation. The degree to which management focuses on results or outcomes rather than on the techniques and processes used to achieve them.

4. People orientation. The degree to which management decisions take into consideration the effect of outcomes on people within the organization.

5. Team orientation. The degree to which work activities are organized around teams rather than individuals.

6. Aggressiveness. The degree to which people are aggressive and competitive rather than easy going.

7. Stability. The degree to which organizational activities emphasize maintaining the status quo in contrast to growth.

Information professionals should have a sense of culture represented in language, decision making, symbols, stories and legends, and daily work practices. For example, every information professional works with a common resource which is information. They also have common practices unique to their profession such as creating, storing, organising, and 
disseminating information for users. Sharing the organization's mission, vision, guiding principles, and values is another common practice an information professional should have. Having a sense of culture has a lot of importance to the information professional in terms of a boundary-defining role; it creates uniqueness and conveys a sense of identity for the professionals. Furthermore, it facilitates commitment to something greater than self-interest. It is the social glue that the members of organisation together. Finally, culture is a sense-making and control mechanism that guides and shapes employees attitudes and behaviour. This last importance is of interest to this paper (Cunha, 2002). Miller (2015) also shared in the same view that culture would encourage information professionals to appreciate where they have come from, who they are now and how they can move into the future.

Information professionals that are motivated and most satisfied when their needs and values are consistent with those manifested in their workplace culture has a strong culture (Heathfield, 2016). An information professional should be "a highly cultured person", meaning such a professional should have certain unique and distinct features such as in language, his choice for literature and research which distinguish him from other professions.

\section{SIXTH SENSE - SENSE OF CREDIBILITY}

Having a sense of creditability is such a hard skill to earn and easy to lose. People will judge you not based on the way you are creative or critical in thinking but based on one's communication. The idea here is making one's words match his actions. In addition to creating landmarks, meeting deadlines, establishing trust is important and vital. Whether an information professional is collaborating, thinking creatively or critically, if there is no trust, achievement will be little and credibility will be lowered. Credibility is a term with so many words related to it; we could say credibility means believability, trust, reliability, honesty, integrity etc. Merriam-Webster dictionary (2016) defined credibility "as the power to inspire belief". Credibility implies a commitment to trust, fairness, and objectivity .Therefore an information professional that has a sense of credibility could be defined as a professional with a believable, trustworthy, and honest sense of managing information and performing information service related duties. Having a sense of credibility is an advantageous sense for those who have it because it boosts opportunities and successes. Budzowski, (2016) listed five key elements to credibility and they are:

\section{Integrity}

A key element of credibility involves transparency, trustworthiness, and moral predictability. . The importance of integrity shouldn't be underestimated. People who are being objective and truthful are perceived to be credible than those who don't. To boost credibility on this element, Cobbe, (2015) suggested the following actions should be taken:

- Invest time in clarifying your values and examining your behavior in light of them

- Build a reputation for truthful and ethical behaviour

- If you make a mistake, be truthful about it rather than cover it up

\section{Competence}

Information professionals who are experts enjoy a much higher degree of credibility than those with low or no expertise. Everyone trusts experts with their issues and projects. Just like a person needing surgery would prefer an experienced surgeon to a just graduated surgeon so will any client prefer an experienced information professional in knowing the right questions to ask, and to know how to find the answers to those questions. Expertise comes from a blend of a person's education and experience. People with doctoral degrees in information related field obviously have more credibility than those who lack a degree. 
At the same time, people who have "come up through the ranks" or have worked in diverse jobs within an industry are considered to be experts. Such people usually have more perceived expertise than new college graduates. Whens a professional is put to test, his Expertise turns into competence. Overtime, an information professional can earn his credibility by succeeding at tasks or assignments over time. For credibility to be increased, Cobbe, (2015) suggested that information professionals should:

- Obtain a degree or a professional certification appropriate to information related field.

- Request high-visibility projects to establish a track record.

- Be proactive in participating with key people in your organization so they can see your competence firsthand.

\section{Sound Judgment}

When wise decisions are to be made, it isn't only managers that make good and sound decisions, when a person can be counted on to analyse complex, situations, make good decisions and ask intelligent questions, such a person could be counted as a credible person. An information professional with sound judgement portrays both cognitive and intuitive skills; he takes on a bigger picture rather than a short term view. A savvy informational professional, for example, might have a track record of acquiring businesses or creating products and services just ahead of demand. This person has a track record of correctly anticipating future trends and preparing for them. For information professional to boost credibility on sound judgement, Cobbe, (2015) suggested the following actions:

- When making decision, ask others for input especially regarding impact on them

- Avoid snap judgments

- Stay current on the trends within your industry and company

\section{Relationally Sensitive}

People with high credibility know how to ask questions about our values and interests, to listen intently and with empathy, and to pull people together. These are the people with high emotional intelligence to balance the arrogance that sometimes comes with expertise. Conger (1998) an expert on persuasion puts it this way: "On the relationship side, people with high credibility have demonstrated-again, usually over time-that they can be trusted to listen and to work in the best interests of others. They have also consistently shown strong emotional character and integrity; that is, they are not known for mood extremes or inconsistent performance" (p. 37). An information professional should develop a track record in relationships with his colleagues in the same way he develops a track record in performance. If he becomes known for building commitment and cooperation, for being levelheaded and fair, everyone will want him on their team. To boost credibility on being relationally sensitive, Cobbe, (2015) suggested the following actions:

- Demonstrate willingness to learn from others and from your own mistakes

- Demonstrate concern for others' values, goals, and objectives

- Take time to understand another's point of view before refuting or rejecting it

\section{Likeable}

Research studies consistently reveal that people respond positively to others whom they like. They trust them, they cooperate with them, they approve their proposals, and they buy from them. Emotional intelligence researchers remind us of the importance of optimism and a light-hearted perspective in the workplace, asserting that leaders who have the ability to express enthusiasm and upbeat emotions attract other people. Furthermore, they remind us that a smile (friendliness) is contagious, drawing others to smile in response. A smile, however, can be faked. Laughter is too complex for faking, and, at a deep, non-verbal level, 
people know this. Accordingly, we trust (assign credibility to) people who laugh with us. To boost your credibility on this element, Cobbe, (2015) suggested the following actions:

- Communicate optimistically by describing challenges rather than problems

- Go out of your way to be friendly, even if you aren't an extravert

- Practice finding the humor around you, especially in stressful situations

- Express gratitude privately, publicly and in writing.

Having a sense of credibility is all in one package. Without credibility, such a professional may not succeed, all the elements listed above interlay with one another and understanding the elements boost success and increases opportunities. With time and consistency, all actions listed above can boost an information professionals credibility in his work place

\section{CONCLUSION AND RECOMMENDATION}

The six senses are important and necessary competence an information professional must have, it is an all in one package. It will enable them to work collaboratively by team building, collaborative medium and with use of suitable technologies, think critically by solving problems, real world problems. With interdisciplinary approach, develop their creativity and innovative skills and communicate effectively and clearly. Information professionals can also build themselves by going for communication building classes to improve their media and digital fluency.

1. When recruiting into information centres, human resources managers have a key role to play, they must be aware of employees that have the six senses and abilities.

2. Information professionals need to be awakened on the need for emerging and new trends especially for creativity and innovation if they want meet up with the current trend in the information world.

3. Continuous professional development should focus more on building collaborative, critical and creative thing, culture, communication and credibility skills in employees.

4. For information centres to regain competitive edge, a new generation of young and information professionals who have some or all of these skills should cover a reasonable percentage of personnel and in the situation where they do not have such skills, they must be ready to learn.

\section{References}

Association of Independent Information professional. (2016). What is an IIP? Retrieved from Association of Independent Information professional: http://www.aiip.org/Discover

Austraian Institute of Business. (2014, June). 6 Reasons why Effective Communiction should be a Focus in Your Business. Retrieved November 16, 2016, from Austraian Institute of Business: http://aib.edu.au/blog/6-reasonseffective-communication-focus-business/

Bates, M. J. (2007). Defining the Information discipline in Encyclopedia Development. Information Research, 12(4). Retrieved November 16, 2016, from http://InformationR.net/ir/12-4/colis/colis29.html.

Bates, M. J., \& Maack,, M. N. (Eds.). (2010). Encyclopedia of Library and Information Sciences. New York: CRC Press.

Boyer, S. (2016). The Importance of Collaboration in the Workplace. Retrieved November 11, 2016, from NutCache: http://www.nutcache.com/blog/the-importance-of-collaboration-in-the-workplace/

Budzowski, B. (2016). Five Keys to crediblity at Work. Retrieved November 12, 2016, from Incredible Messages, LP: http://incrediblemessages.com/five-keys-to-credibility-at-work/

Cambridge Advanced Learners Dictionary. (2016). Meaning oof Sense. Retrieved from Cambridge Advanced Learners Dictionary: http://dictionary.cambridge.org/dictionary/english/sense

Chatman, J. A. \& Jehn, K. A. (1994). Assessing the Relationship Between Industry Characteristics and Organizational Culture: How Different can you be? Academy of Management Journal, 522-553.

Conger, J. A. (May June 1998). The Necessary art of Persuasion. Havard Business Review, 33-44. 
Cunha, M. P. (2002). The 'Best Place to Be: Managing Control and Employee Loyalty in a Knwledge-Intensive Company. Journal of applied Behavioural Science, 481-495.

Dalkir, K. (2005). Knowledge Management in Theory and Practice. Butterworth-Heinemann: Elsevier.

Elder, L. , Paul, R. \& Cosgrove, R. (2007, December). International Critical Thinking and basic Concepts and Understanding Test: Assessing the initial understanding of basic critical thinking concepts and principles. Foundation for Crtical Thinking. Retrieved from http://www.criticalthinking.org/pages/international-criticalthinking-basic-concepts-amp-understan/782

Facione, P. A. (1998). Critical Thinking: A Statement of expert consensus for the purposes of educational assessment and instruction. Fullerton: Insight Assessment. Retrieved from

http://www.insightassessment.com/Resources/Expert-Consensus-on-Critical-Thinking/Delphi-ConsensusReport-Executive-Summary-PDF

Foundations of Critical Thinking. (2015). The Critical Thinking Community. Retrieved from Criticalthinking.org: http://www.criticalthinking.org/pages/critical-thinking-where-to-begin/796

Hansen, B. (2016, May 24). 6 Challenges to Team Collaboration. Retrieved November 11, 2016, from Wrike Inc.: https://www.wrike.com/blog/6-challenges-team-collaboration/

Harris, R. (April, 2012 2). Introduction to Creative Thinking. Retrieved from Virtul Salt: http://www.virtualsalt.com/crebook1.htm

Heathfield, S. M. (2016, November 13). What Makes Up Your Company Culture?Integrating New Employees in Your Existing Culture Is an Achievable Goal . Retrieved November 16, 2016, from The Balance: https://www.thebalance.com/what-makes-up-your-company-culture-1918816

Its not the same thing - the 3 types of collaboration. (2010). Retrieved November 11, 2016, from Product Four:the reinvention of work and marketing: https://productfour.wordpress.com/2010/03/20/its-not-the-same-thingthe-3-types-of-collaboration/

Johnson, R. (2016). What Are the Benefits of Effective Communication in the Workplace? Retrieved November 16, 2016, from Small Business: http://smallbusiness.chron.com/benefits-effective-communication-workplace20198.html

Kim, B. (2014). Why Every Person Should Develop Creative Thinking Skills. Retrieved from BrianKim.net: http://briankim.net/articles/every-person-develop-creative-thinking-skills/

Lai, E. (2011). Collaboration: A Literature Review. Pearson Publisher. Retrieved November 11, 2016

Luecke, R. \& Katz, R. (2003). Managing Creativity and Innovation. Boston, MA: Harvard Business School Press.

Merriam-Webster. (2016). Meaning of Credibility. Retrieved from Merriam-Webster Incorporated: http://www.merriam-webster.com/dictionary/credibility

Miller, B. S. (2015, June 01). The 6 C's Squared Version of Education in the 21st Century. Retrieved from BAM Radio Network: http://www.bamradionetwork.com/edwords-blog/the-6-c-s-squared-version-of-education-in-the21st-century

Paul R. \& Elder, L. (2008). The Thinker's Guide to the nature and Functions of Critical \& Creative Thinking. Foundation for Critical Thinking Press. Retrieved from www.criticalthinking.org

Robbin, S. P. \& Timothy, J. A. (2013). Organizational Behaviour (15th ed. ed.). Upper Saddle River, New Jersey: Pearson Education, Inc.

Sharma, A. (2016). Creative Thinking: 4 Stages of Creativity Thinking. Retrieved from Psychology Discussion. Net: http://www.psychologydiscussion.net/mind/creative-thinking-4-stages-of-creativity-thinking/610

Skills You Need. (2016). What is Communication. Retrieved November 16, 2016, from Skills You Need: http://www.skillsyouneed.com/general/what-is-communication.html

Wilson, L. O. (2016). TheSecond principle. Retrieved November 11, 2016, from Church WordPress Theme by themehall.com: http://thesecondprinciple.com/creativity/creativity-essentials/types-of-creative-thinking/ 